\title{
Périgueux - 3 place de la Cité
}

$n^{\circ} 026100$

\section{Vanessa Elizagoyen}

\section{(2) OpenEdition}

Journals

Édition électronique

URL : http://journals.openedition.org/adlfi/16419

ISSN : 2114-0502

Éditeur

Ministère de la culture

Référence électronique

Vanessa Elizagoyen, «Périgueux - 3 place de la Cité », ADLFI. Archéologie de la France - Informations

[En ligne], Aquitaine, mis en ligne le 10 février 2016, consulté le 19 avril 2019. URL : http://

journals.openedition.org/adlfi/16419

Ce document a été généré automatiquement le 19 avril 2019

(c) Ministère de la Culture et de la Communication, CNRS 


\title{
Périgueux - 3 place de la Cité
}

\author{
$n^{\circ} 026100$
}

\section{Vanessa Elizagoyen}

Lien Atlas (MCC) :

http://atlas.patrimoines.culture.fr/atlas/trunk/index.php?

ap_theme=DOM_2.01.02\&ap_bbox=-0.674;45.174;0.747;45.214

1 Un diagnostic archéologique a été réalisé à la Cité de Périgueux à la suite d'une demande volontaire émanant de la mairie de Périgueux qui envisage la restructuration de l'école primaire de ce quartier.

2 Deux sondages ont été effectués, un dans chacune des cours de l'école. Malgré des contraintes importantes, l'opération a permis d'obtenir des résultats significatifs quant à l'occupation humaine de la zone, située au cœur de la ville antique puis de la ville médiévale de la Cité.

3 Ainsi, le sondage 1 a révélé un angle de bâti formé de deux murs dégagés au maximum sur $1,80 \mathrm{~m}$ de hauteur et associés à un sol US 1011. Une structure en creux creusée dans ce sol est datée entre le $\mathrm{xI}^{\mathrm{e}}$ et le $\mathrm{xIII}{ }^{\mathrm{e}} \mathrm{s}$. Un bouchon observé dans le mur d'axe nord-sud, associé au dégagement partiel de pierres enchâssées dans un mortier jaune, permet de supposer la présence d'un troisième mur d'axe est-ouest constituant la limite septentrionale de l'US 1011.

4 Dans l'espace en « U » matérialisé par l'angle de mur, un sondage profond a permis de constater l'absence de couches contemporaines à cet endroit où des niveaux, probablement du Haut Moyen Âge, sont recouverts de remblais attribués au XIV ${ }^{\mathrm{e}} \mathrm{s}$. La configuration de cet espace et l'élévation importante des murs mis au jour invitent à y situer un aménagement de type cave.

5 Malheureusement, l'instabilité du terrain, due à la présence d'un remblai de démolition moderne, a empêché d'atteindre les niveaux antiques.

6 Le sondage 2 se trouve dans la petite cour au nord de l'école, à proximité immédiate de l'église Saint-Etienne de la Cité, mentionnée depuis le $\mathrm{xI}^{\mathrm{e}} \mathrm{s}$. Un mur orienté nord-sud, identique dans sa mise en œuvre à ceux du sondage 2, a été mis en évidence, appuyé 
contre un mur plus ancien, d'un mètre d'épaisseur et d'axe est-ouest, sans doute construit à partir d'éléments de remplois. Dans la partie nord du sondage, des niveaux en place ont pu être enregistrés, scellés par un remblai attribué à une fourchette de datation comprise entre le $\mathrm{x}^{\mathrm{e}}$ et le $\mathrm{XII}^{\mathrm{e}} \mathrm{s}$. Ainsi, un aménagement formé de blocs posés à plat et de pavés jointifs pris dans un mortier jaune et marquant une forte déclivité vers le nord pourrait correspondre à un niveau de sol d'un bâtiment ou à la bordure méridionale d'un axe de voirie orienté est-ouest. Un trou de poteau a pu être mis en évidence, creusé dans cette US. Sous cet aménagement indéterminé et peut-être en lien avec l'épais mur est-ouest se développant au sud, deux niveaux de sol de mortier ont été découverts à environ $1,85 \mathrm{~m}$ de profondeur, fonctionnant de façon contemporaine avec un mur nord-sud uniquement vu en coupe. L'absence de mobilier archéologique associé à ces vestiges empêche de leur attribuer une datation fiable. Tout au plus peut-on se permettre de les situer avant le $\mathrm{XI}^{\mathrm{e}}$ s.

7 Ces couches et structures reposent sur un limon sableux noir incluant de petits éléments et ayant livré des tessons de céramique du $\mathrm{II}^{\mathrm{e}} \mathrm{s}$. À la base de ce probable remblai, un dernier mur orienté est-ouest apparait, à environ $2,80 \mathrm{~m}$ de profondeur.

Malgré des conditions de réalisation ayant limité la qualité de l'intervention, ce diagnostic s'avère plus que positif quant à la densité de vestiges archéologiques qu'il a permis de mettre en lumière, de la période antique au Moyen Âge.

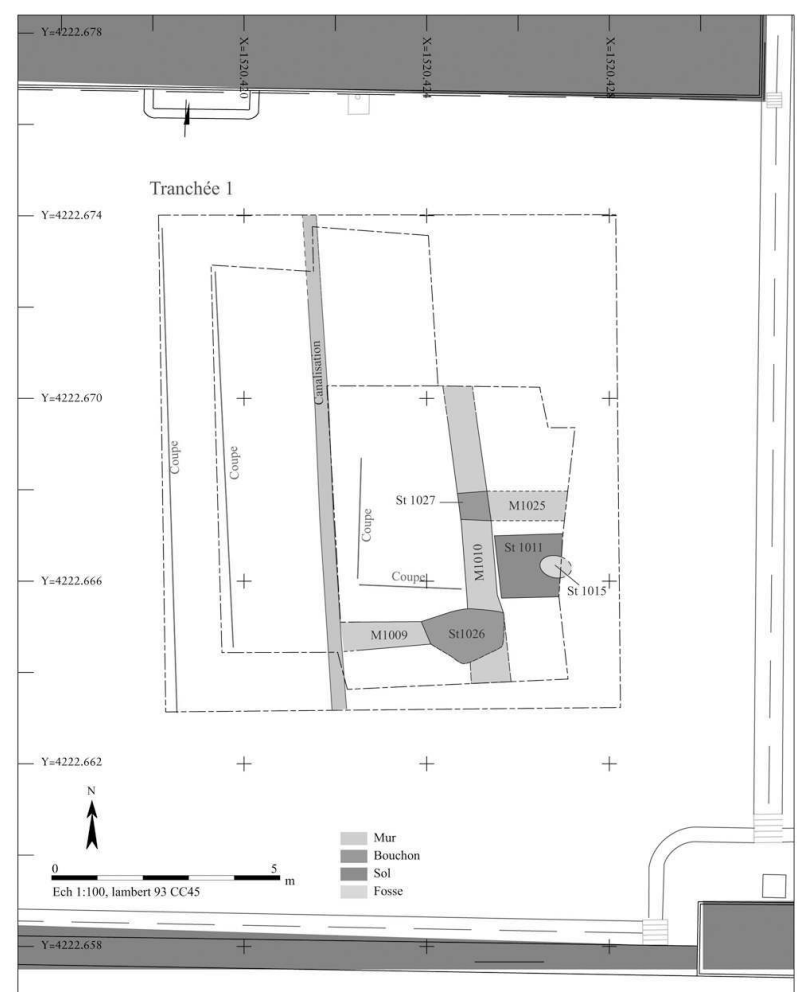

Fig. 1

Plan topographique du sondage 1 au 1/100e.

DAO : V. Pasquet, C. Mangier, C. Fondeville, Inrap. 


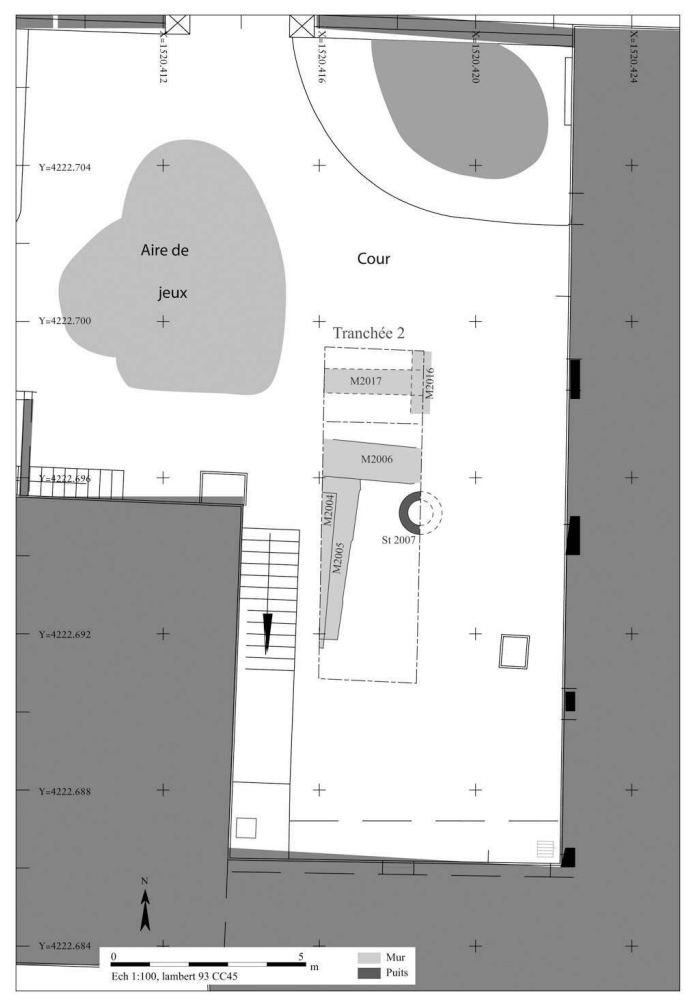

Fig. 2

Plan topographique du sondage 2 au $1 / 100^{\mathrm{e}}$.

DAO : V. Pasquet, C. Mangier, Inrap.

INDEX

Index géographique : Aquitaine, Dordogne (24), Périgueux

Index chronologique : Moyen Âge

operation Opération préventive de diagnostic (OPD)

Mots-clés : bâti

\section{AUTEURS}

VANESSA ELIZAGOYEN

Inrap 